\title{
Só para não passar em branco: uma revisão narrativa sobre a branquitude
}

Vanessa Pita Sousa 1 (i)

Universidade Federal do Recôncavo da Bahia

Dóris Firmino Rabelo

Universidade Federal do Recôncavo da Bahia

Jeane Saskya Campos Tavares ${ }^{3}$ (i)

Universidade Federal do Recôncavo da Bahia

Artigos livres | Free articles | Articulos libres

DOI do artigo: 10.22481/odeere.v6i2.8730

RESUMO

Este artigo objetiva realizar uma revisão narrativa sobre a temática da branquitude, de modo a verificar suas definições presentes na literatura, assim como as maneiras como ela se expressa no cotidiano. As produções foram organizadas em um quadro segundo autor e data, discutindo os diferentes aspectos da raça, na realidade brasileira, em diferentes regiões e também da realidade de outros países. As informações obtidas indicam que a branquitude, em suas diversas representações, configura-se um agente central na manutenção do racismo. Foram identificados os problemas da não racialização e os prejuízos centenários dessa relação de poder. É um panorama diverso e complexo, que compreende pessoas com ou sem consciência de si, com variados níveis de privilégios, expressos territorial, material e simbolicamente de maneiras diferentes.

Palavras chave: Branquitude; Raça; Desigualdades; Racismo; Racialização.

\section{Just to not go in White: a narrative review of whiteness ABSTRACT}

This article attempts to develop a narrative review on the whiteness theme, in order to verify its definitions in the literature, as well as the ways in which it is expressed in daily life. The productions were organized in a table according to the author and date, discussing the different aspects of the race, in the Brazilian reality, in its different regions and also in the reality of other countries. The information collected indicate that whiteness, in its various representations, is a central agent for maintaining racism. The problems of non-racialization and the centuries-old damage of this power relations were identified. It is a diverse and complex scenery, which comprises people with or without self-awareness, with varying levels of privileges, expressed territorially, materially and symbolically in different ways.

Keywords: Whiteness; Race; Inequalities; Racism; Racialization

\section{Submetido em: 15/05/2021 | Aceito em: 24/11/2021}

\footnotetext{
1 Especializanda em Psicologia, Avaliação e Atenção à Saúde pela UFRB- Universidade Federal do Recôncavo da Bahia Técnica de Psicologia CREAS - Centro de Referência Especializado da Assistência Social- do Município de Quijingue-BA Diretora suplente do Sindicato dos Psicólogos da Bahia (2018-2021) Conselheira Estadual da Assistência Social/CEAS-BA (2020). E-mail: vanessa.pita@gmail.com

2 Graduação em Psicologia pela UFU, Mestrado em Gerontologia pela UNICAMP e Doutora em Educação pela mesma universidade. Docente CCS/UFRB, PPGPSI/UFBA e do Mestrado Profissional em Saúde da Família - ProfSaúde-UFRB. GT Relações Intergrupais, Preconceito e Exclusão Social da ANPEPP. Diretoria da Associação Brasileira de Psicologia do Desenvolvimento (Gestão 2020-2022). Coordena o GT Psicologia, Envelhecimento e Velhice do CRP-03. E-mail: drisrabelo@ufrb.edu.br

3 Graduada em Psicologia pela Universidade Federal da Bahia (UFBA), mestre em Saúde Comunitária e doutora em Saúde Pública pelo ISC/UFBA. Docente Universidade Federal do Recôncavo da Bahia (UFRB), Membro da Comissão de Direitos Humanos do Conselho Federal de Psicologia CDH-CFP). Membro colaborativo do GT de saúde da pop negra da Sociedade Brasileira de Medicina de família e Comunidade (SBMFC). E-mail: jeanetavares@ufrb.edu.br
}

open Oaccess ODEere, v. 6, n. 2, jul./dez., p. 352-368, 2021. 
O mito da democracia racial ${ }^{4}$, ideia amplamente difundida no Brasil, trata da suposta convivência harmoniosa entre as diferentes raças no território brasileiro. O conceito de boa convivência inter-raças ganhou proporções internacionais e, apesar de contestado tanto pelos movimentos sociais quanto pela ciência, suas repercussões ainda têm força para conservar privilégios e promover desigualdades 5 . Esse mito é substrato para a base material do racismo, meio da sua manutenção, e está a serviço dos interesses postos pelo capitalismo.

Decorrido o período de escravização enquanto sistema econômico predominante e libertação da população negra no Brasil, os ex-escravizados foram relegados a uma condição de orfandade social, ao passo que foram incentivadas imigrações de europeus brancos, em sua maior parte italianos e alemães, que receberam insumos para o trabalho e permanência no Brasil. O objetivo por detrás do apadrinhamento dos grupos vindos da Europa como uma política pública era miscigenar o país até a negrura trazida de África desaparecerb. Assim, os aspectos do ideal de branqueamento estão por toda parte, inclusive na mestiçagem.

É desafiador romper com o mito da democracia racial e o ideal de branqueamento, tão impregnado desde muito tempo. Uma análise menos cuidadosa acabará por fazer com que se atribua o racismo e todas as mazelas sobrevindas dele aos resquícios da abolição, o que significaria dizer que as pessoas negras e não brancas são culpadas pelas opressões, preconceitos e prejuízos dos quais são vitimados, com as devidas comprovações históricas. É preciso ir adiante nesse entendimento, identificar os interesses e poderes que comandam 0 funcionamento social. Com a abolição da escravização, foram pensados novos recursos de manutenção de poder, que afetariam, geração após geração, a população negra do país ${ }^{7}$

Ser branco orienta a noção de não pertencimento a todos que não são brancos. Desse modo, a presença da brancura de um povo demarcou as diferenças além de tons de epiderme, revelou um grupo social submetido ao poder

\footnotetext{
${ }^{4}$ MUNANGA, Kabengele; Gomes, Nilma L. O negro no Brasil de hoje. São Paulo: Global, 2006.

5 GOMES, Janaína D. Os segredos de Virgínia: estudo de atitudes raciais em São Paulo (1945-1955). Tese de Doutorado da Faculdade de Filosofia, Letras e Ciências Humanas, Universidade de São Paulo, São Paulo, 2013. Recuperado de: https://teses.usp.br/teses/disponiveis/8/8134/tde-14032014103244/publico/2013_JanainaDamacenoGomes.pdf

6 CONSELHO FEDERAL DE PSICOLOGIA. Relações Raciais: Referências técnicas para a atuação de psicólogas(os). Brasília: CFP, 2017.

7 BACELAR, Jeferson. A hierarquia das raças: Negros e Brancos em Salvador. Rio de Janeiro: Pallas, 2008
} 
de outro grupo hegemônico. O branco era visto como norma a ser obedecida e seus atributos impregnaram-se no ideário social, isento de precisar afirmar sua identidade 8 .

Carone e Bento'9 recomendam dar nome de branquitude a esse sistema que esconde privilégios e desigualdades, além de inscrevê-la, sem hesitações, em uma categoria racial e compreender os fenômenos atribuídos a ela. Esta é condição sine qua non ao estudo das relações raciais no país de maneira legítima. Segundo as autoras, a branquitude se constitui pelo medo da ascensão do povo negro e pelos pactos narcísicos que pessoas brancas estabelecem entre si.

A branquitude é a base do racismo à brasileira, uma modalidade velada de discriminação, de característica estrutural, que dá sentido às relações entre as pessoas desse contexto ${ }^{10}$, à maneira como se percebem ou são impedidas de se perceberem. Desse modo, assegura privilégios a uma elite de suposta superioridade, porém não se fala a respeito, pois poderia ser muito perigoso assumir as contradições de ser o modelo de humanidade e, ao mesmo tempo sequer ser humano, ser perfeito e precisar encarar suas imperfeições ${ }^{11}$. Como consequência há a contradição de a raça branca, ao assumir o falso lugar de superioridade, também se desumanizar, pois não cogita a própria existência humana, do mesmo modo em que não corresponde aos atributos sobre-humanos que inventou para $\mathrm{si}^{12}$

Não à toa Guerreiro Ramos'13 em "A patologia social do branco brasileiro", questiona sobre como pessoas brancas não se percebem como categoria racial socialmente construída e ressignifica o estudo das relações raciais brasileiras, apenas pela via da observação de toda diversidade de sua população. Por isso, deve-se incluir a população branca nessas análises.

Para tanto é importante identificar as variadas definições de branquitude propostas pela literatura, considerando como ela se expressa no cotidiano brasileiro e quais os mecanismos ocultos que a sustentam. Restringir privilégios a

\footnotetext{
8 FANON, Frantz. Pele negra, máscaras brancas. Salvador: EDUFBA, 2008.

9 CARONE, Iray; Bento, Maria Aparecida S. Psicologia social do racismo: estudos sobre branquitude e branqueamento no Brasil. Petrópolis: Vozes, 2003.

10 ALMEIDA, Silvio L. Racismo estrutural. São Paulo: Pólen, 2019.

11 CARONE, Iray; Bento, Maria Aparecida S. Psicologia social do racismo: estudos sobre branquitude e branqueamento no Brasil. Petrópolis: Vozes, 2003

12 Idem.

${ }^{13}$ RAMOS, Alberto G. Introdução crítica à sociologia brasileira. Rio de Janeiro: Editora da UFRJ, 1995.
} 
uma categoria racial tem por consequência aumentar as discrepâncias raciais existentes na sociedade brasileira. Essa incursão no estudo da branquitude poderá facilitar compreensão mais profunda da realidade das relações raciais do Brasill14.

Discutir branquitude é uma iniciativa de utilidade pública, cara a todas as categorias raciais. Até então, as questões raciais eram consideradas problema exclusivo da população negra e não branca, em total acordo com o modelo branco, tido como ideal, normatizado sem qualquer questionamento. Os estudos sobre a temática não são recentes, mas precisam ainda de maior investimento e visibilidade. $O$ incômodo de ser negro é uma invenção genuinamente branca, embora isso não seja declarado.

A psicologia, por sua vez, deve assumir seu compromisso humano, social e ético, a fim de prestar um serviço qualificado. Referenda em seu manual de conduta, ${ }^{15}$, que profissionais a ele submetido devem atentar ao que versa a Declaração Universal dos Direitos Humanos, dedicando-se a eliminar toda sorte de "negligência, discriminação, exploração, violência, crueldade e opressão". A determinação confirma o compromisso da psicologia no combate ao racismo, até por respeito à própria normativa. Psicólogos e psicólogas devem primar pela qualidade de vida da humanidade, intervir de acordo com o panorama social, em seus aspectos históricos, culturais, políticos e econômicos ${ }^{16}$.

Dessa forma, este artigo trata de uma revisão narrativa acerca da branquitude, considerando as definições presentes na literatura e sobre como ele opera no cotidiano. É importante perceber a relação entre branquitude e os contrastes raciais existentes no Brasil, pois as pessoas podem expressar sua consciência racial de maneiras muito diferentes ${ }^{17}$. Além do que, há mais tipos de branco do que se pode presumir, conforme recomenda Schucman ${ }^{18}$. Perceber o

\footnotetext{
14 SCHUCMAN, Lia V. Entre o "encardido", o "branco" e o "branquíssimo": raça, hierarquia e poder na construção da branquitude paulistana, Tese de Doutorado do Instituto de Psicologia, Universidade de São Paulo, São Paulo, 2014. Recuperado de: https://www.teses.usp.br/teses/disponiveis/47/47134/tde-21052012-

154521/publico/schucman_corrigida.pdf

15 CONSELHO FEDERAL DE PSICOLOGIA. Resolução CFP n. ${ }^{\circ}$ 010: Código de Ética do Profissional Psicólogo. Brasília: CFP, 2005, p. 7.

16 op.cit.

17 CARDOSO, Lourenço C. Branquitude acrítica e crítica: A supremacia racial e o branco antiracista. Revista Latinoamericana de Ciencias Sociales, Niñez y Juventud, vol 8, N. 1, Janeiro de 2010, p. 607-630.

18 SCHUCMAN, Lia V. Entre o "encardido", o "branco" e o "branquíssimo": raça, hierarquia e poder na construção da branquitude paulistana, Tese de Doutorado do Instituto de Psicologia, Universidade de São

Paulo,

São

Paulo,

2014.

Recuperado

de:
} 
panorama racial do país possibilita proposição de estratégias para sanar o sofrimento psíquico ocasionado pelo racismo.

\section{Método}

Trata-se de uma revisão narrativa, como recomendando por Hohendorff 19 , em razão de se prestar a descrever e discutir o estado da arte sobre o assunto, permitindo análise crítica do autor. A modalidade se ocupa de ampla análise da literatura, sem estabelecer os parâmetros de generalização próprios de estudos quantitativos. Busca definir um determinado problema, sumarizando estudos prévios e informando o estado em que se encontra o tema selecionado. Visa aglutinar ideias de autores diferentes, não possui um formato pré-estabelecido e, embora sejam utilizados descritores e bases de dados, não descreverá o processo de busca pelas publicações consultadas como feito em revisões sistemáticas da literatura.

Para a confecção deste artigo buscou-se produções textuais relacionadas ao tema da branquitude, a fim de encontrar construções teóricas pertinentes ao tema, que tratassem diretamente sobre branquitude e aspectos correspondentes, de modo que a investigação não recaísse no foco da negritude ou racismo. Foi feita uma seleção das publicações cujos títulos trouxessem os termos branquitude, branco/a ou que fizesse alguma menção indireta à raça branca.

Foram analisadas qualitativamente produções científicas acerca da branquitude, a fim de descortinar as definições propostas por diversos autores e autoras, assim como evidenciar como ela opera no cotidiano. Foram incluídos livros, artigos, cadernos de orientações técnicas, Código de Ética da Psicologia, teses e dissertações, consultadas em bases científicas de dados: Scielo, Lilacs, Medline e Psycinfo, além do Catálogo de Teses e Dissertações CAPES, com acréscimo de outras obras de especialistas com trabalhos de repercussão na área, de modo a ampliar o banco de dados.

Foram também realizadas também leituras de livros clássicos e manuais que fomentam discussões sobre relações raciais que, embora não ponham a branquitude no centro da discussão, constituem um robusto insumo teórico para 
estudar diferentes vieses possíveis nos estudos de raça. Ademais, as fontes tradicionais possibilitam estabelecer uma dimensão histórica mais apurada. De posse das leituras do acervo construído sobre a temática foram sumarizadas as definições sobre branquitude e termos que evidenciavam o modo como ela se expressa no dia-a-dia das relações interpessoais estabelecidas no país. O processo se deu de maneira não sistemática, mas a partir da verificação da análise crítica dos autores, cujos conteúdos são referências dessa seara.

\section{Resultados e discussão}

Os dados foram agrupados de modo a demonstrar as variadas definições de branquitude encontradas na literatura ao longo do tempo, e os modos como ela opera no cotidiano, a partir de seus respectivos autores e períodos das publicações analisadas nesse artigo. Não obstante diferentes conceitos localizados, houve muitas afinidades entre os termos utilizados pelos diferentes teóricos, conforme demonstra o Quadro 1. 


\section{Quadro 1}

\begin{tabular}{|c|c|c|c|c|}
\hline Período & Autor & Tipo de texto consultado & Definição de branquitude & Como a branquitude opera no cotidiano \\
\hline 1983 & Santos, Neusa Souza & Livro & $\begin{array}{l}\text { Almejada } \\
\text { Parâmetro } \\
\text { Cruel }\end{array}$ & Ideologia do branqueamento \\
\hline 2003 & Bento, M.A.S & Livro & $\begin{array}{l}\text { Categoria não racializada } \\
\text { Narcisista }\end{array}$ & $\begin{array}{l}\text { Narcisismo } \\
\text { Projeção } \\
\text { Medo }\end{array}$ \\
\hline 2006 & Munanga, Kabengele & Livro & $\begin{array}{l}\text { Invisível } \\
\text { Não racializada }\end{array}$ & $\begin{array}{c}\text { Mestiçagem } \\
\text { Branqueamento } \\
\text { Mito da democracia racial } \\
\text { Apagamento da população não branca }\end{array}$ \\
\hline 2008 & Fanon, Frantz & Livro & $\begin{array}{l}\text { Almejada } \\
\text { Parâmetro }\end{array}$ & $\begin{array}{c}\text { Universal } \\
\text { Regulador das relações humanas }\end{array}$ \\
\hline 2009 & Sovik, Liv & Livro & $\begin{array}{l}\text { Diversa } \\
\text { Privilegiada } \\
\text { llegítima }\end{array}$ & Branquitude "por aproximação" \\
\hline 2010 & Cardoso, Lourenço & Artigo & $\begin{array}{l}\text { Branquitude Consciente de si } \\
\text { Branquitude Insconsciente de si }\end{array}$ & $\begin{array}{l}\text { Criticidade } \\
\text { Acriticidade }\end{array}$ \\
\hline 2011 & Huijg, Dieuwertje Dyi. & Artigo & Incoerente & Ignora o lugar de privilégio \\
\hline 2012 & $\begin{array}{l}\text { Schucman, Lia Vainer; } \\
\text { Serra, Lia Novais. }\end{array}$ & Artigo & $\begin{array}{c}\text { Suposta superioridade e } \\
\text { pureza racial }\end{array}$ & Desvalorizando pessoas \\
\hline 2013 & Gomes, Janaína D. & Tese de doutoramento & Cruel & $\begin{array}{c}\text { Causa sofrimento à população negra; utiliza o mito } \\
\text { da democracia racial para esconder privilégios e } \\
\text { poder de opressão }\end{array}$ \\
\hline 2013 & Nogueira, Simone Gibran & Artigo & Colonizadora & $\begin{array}{c}\text { Interfere na desumanização mental e colonização } \\
\text { de brancos e negros }\end{array}$ \\
\hline 2014 & $\frac{\text { Corossacz, Valeria }}{\text { Ribeiro. }}$ & Artigo & $\begin{array}{l}\text { Contraditória } \\
\text { Privilegiada }\end{array}$ & $\begin{array}{l}\text { Nega a própria branquitude utilizando-se da } \\
\text { relação com a negritude }\end{array}$ \\
\hline 2014 & Schucman, Lia Vainer & Livro & Heterogênea & $\begin{array}{l}\text { Brancos que oprimem outros brancos; Vantagens } \\
\text { relacionadas a tons mais claros de epiderme }\end{array}$ \\
\hline 2014 & Schucman, Lia Vainer & Artigo & Equivocada & $\begin{array}{c}\text { Racista; } \\
\text { Suposta superioridade }\end{array}$ \\
\hline 2016 & Davis, Angela & Livro & $\begin{array}{l}\text { Perversa } \\
\text { Vaidosa }\end{array}$ & $\begin{array}{l}\text { Detentora do saber } \\
\text { Colonizadora }\end{array}$ \\
\hline 2016 & Geler, Lea. & Artigo & $\begin{array}{l}\text { Valorizada } \\
\text { Hegemônica }\end{array}$ & $\begin{array}{l}\text { Impede a existência do Mestiço; } \\
\text { Força a hegemonia da branquitude; cria tipos de }\end{array}$ \\
\hline
\end{tabular}




\begin{tabular}{|c|c|c|c|c|}
\hline & & & $\begin{array}{l}\text { Padrão de excelência } \\
\text { Ausência/tipo de cor }\end{array}$ & negritude \\
\hline 2017 & $\begin{array}{l}\text { Conselho Federal de } \\
\text { Psicologia }\end{array}$ & $\begin{array}{c}\text { Manual de Referências } \\
\text { Técnicas }\end{array}$ & Não racializada & $\begin{array}{c}\text { Privilegiada pelas barreiras sociais; invisibilizada na } \\
\text { prática das/os profissionais psicólogas/os }\end{array}$ \\
\hline 2018 & DiAngelo, Robin & Livro & $\begin{array}{l}\text { Super protegida } \\
\text { Frágil }\end{array}$ & $\begin{array}{l}\text { Despreparo para lidar com tensões raciais; } \\
\text { Evita que as questões raciais sejam debatidas }\end{array}$ \\
\hline 2019 & Meireles et.al & Artigo & $\begin{array}{l}\text { Preconceituosa; } \\
\text { Engajada; } \\
\text { Inovadora }\end{array}$ & $\begin{array}{c}\text { Disposta a combater iniquidades; } \\
\text { Constrói insumo intelectual para o combate ao } \\
\text { racismo }\end{array}$ \\
\hline 2019 & Santiago, Flávio. & Artigo & $\begin{array}{c}\text { Privilegiada; } \\
\text { Supremacista; Especificidade } \\
\text { da masculinidade branca }\end{array}$ & $\begin{array}{c}\text { Trata a raça negra com alteridade; } \\
\text { transmissão da estética branca para crianças } \\
\text { pequenas }\end{array}$ \\
\hline 2020 & $\begin{array}{l}\frac{\text { Butler, Judith; }}{\text { Fabiana A. A. }} ; \frac{\text { Teixeim, }}{\text { Teira, }} \\
\frac{\text { Jacqueline }}{\text { Moraes; Rinaldi, }} \\
\text { Sebastião }\end{array}$ & Artigo & $\begin{array}{l}\text { Racista; } \\
\text { Paranóica }\end{array}$ & $\begin{array}{c}\text { Impunidade; } \\
\text { Violência; } \\
\text { Medo; } \\
\text { Percepção impregnada pelo racismo }\end{array}$ \\
\hline 2020 & Cardoso, Lourenço & Livro & $\begin{array}{c}\text { Vaidosa } \\
\text { Detentora do poder }\end{array}$ & Tenciona fazer do negro objeto de pesquisa; \\
\hline 2020 & de; $\frac{\frac{\text { Oliveira, Daniele }}{\text { Resende, Viviane de }}}{\underline{\text { Melo. }}}$ & Artigo & $\begin{array}{l}\text { Detentora do poder de } \\
\text { discurso; } \\
\text { Racista } \\
\text { Privilegiada }\end{array}$ & Dominação \\
\hline 2020 & Ortiz-Piedrahíta, Vanessa. & Artigo & $\begin{array}{c}\text { Branquitude Crítica; Acrítica; } \\
\text { Mestiça }\end{array}$ & Hegemonia \\
\hline 2021 & $\begin{array}{l}\text { Eurico, Márcia; } \\
\text { Gonçalves, Renata; } \\
\text { Fornazier Tales }\end{array}$ & Artigo & $\begin{array}{l}\text { Detentora do poder } \\
\text { biopolítico }\end{array}$ & $\begin{array}{l}\text { Opressão; aniquila vidas negras; } \\
\text { Letalidade; }\end{array}$ \\
\hline
\end{tabular}


A partir da compreensão do quadro acima e das leituras realizadas sobre branquitude, verificou-se que ela não se apresenta a partir de um discurso único e pode ser observada a partir de diferentes perspectivas. Embora não haja consenso absoluto a respeito de suas definições e sobre o modo como ela se expressa, são observados alguns pontos coincidentes no que diz respeito a esse grupo racial. Há diversidade mesmo dentro da própria branquitude ${ }^{20}$. O branco se apresenta como padrão racial que norteia os demais sujeitos e são evidenciados privilégios dessa categoria racial em relação às demais21. Serão abordados os diferentes achados sobre a temática e analisados também os pontos em que as literaturas se cruzam.

Tanto para Neusa Santos 22 quanto para Fanon, a branquitude consiste em um suposto ideal de perfeição a ser atingido por toda a sociedade, embora esse ideal seja nitidamente intangível. Os autores propõem uma expressão profunda da branquitude, que atinge níveis inconscientes das relações humanas, engendrando padrões nocivos de relações interpessoais.

Mais adiante Carone e Bento23, abordariam os contrastes sociais entres brancos e não brancos, mas conferiram especial atenção ao fato de não se falar sobre raça branca e sobre a prática costumaz de não se debater a respeito. Essas autoras, debruçam-se sobre a temática, de forma a revelar o narcisismo da branquitude, o modo como seres humanos brancos cooperam entre si para manter e perpetuar privilégios, além de um medo evidente de que esse acordo seja descoberto. Não falar a respeito oportuniza ao sujeito branco não atentar a si mesmo e às suas atitudes, afirmam.

O Conselho Federal de Psicologia ${ }^{24}$ também se insere nas discussões raciais no Brasil. Em um intervalo de doze anos, o Conselho persiste em tornar a categoria profissional ciente de que há barreiras raciais a serem superadas e, mais do que isso, registra documentos que afirmam o compromisso social que devem assumir seus credenciados ao tornarem-se psicólogos. Destaca,25, que a questão é ainda

20 ORTIZ-PIEDRAHÍTA, Vanessa. (2020). Subjetivación de la blanquitud por jóvenes universitarios: un estudio comparativo. Revista Latinoamericana de Ciencias Sociales, Niñez y Juventud, abrilde 2020, volume 18, N. 1, p. 183-206. Doi: https://doi.org/10.11600/1692715x.18109

${ }^{21}$ FANON, Frantz. Pele negra, máscaras brancas. Salvador: EDUFBA, 2008

22 SOUZA, Neusa S. Tornar-se Negro. Rio de Janeiro: Edições Graal, 1983.

23 CARONE, Iray; Bento, Maria Aparecida S. Psicologia social do racismo: estudos sobre branquitude e branqueamento no Brasil. Petrópolis: Vozes, 2003

${ }^{24}$ CONSELHO FEDERAL DE PSICOLOGIA. Relações Raciais: Referências técnicas para a atuação de psicólogas(Os). Brasília: CFP, 2017.

25 Ibidem. 
muito invisibilizada, apesar de os profissionais lidarem com relações raciais em suas práticas. Convém mencionar que as bases curriculares da ciência psicológica brasileira são brancas, de natureza eurocêntrica, apesar de todo o empenho do Conselho em atentar-se à diversidade de seres humanos.

Não obstantes as diferenças identificadas nas construções das raças na sociedade, pode-se identificar mecanismos que fazem com que elas se fortaleçam. Munanga 26 foi incisivo ao confirmar que não houve democracia racial em qualquer tempo no Brasil. O pai do termo "mito da democracia racial" entendeu a mestiçagem como mais um recurso de branqueamento e apagamento da população não branca. Essa compreensão da realidade traz à tona as questões relativas ao colorismo e a crença de que os mestiços seriam considerados melhores por serem mais próximos da branquitude, ao mesmo tempo em que eram tornados sem valor pelos seus atributos negroides.

Outra autora estrangeira27, manifesta interesse pelo estudo das relações raciais brasileiras e concede um panorama de uma pesquisadora europeia branca que há muito vive no Brasil e observa as correspondências entre a branquitude brasileira e a branquitude observada na Europa. De acordo com a autora, existe um discurso, fruto do mito da democracia racial, de que não existiriam pessoas genuinamente brancas no Brasil, em razão da forte miscigenação, porém, pessoas de fenótipo branco, ainda que brancos ilegítimos, desfrutam dos mesmos privilégios raciais de europeus em território nacional. Para ela, trata-se de uma tentativa inútil de silenciar a discussão racial, além da negação dos privilégios acumulados durantes anos. Salienta que o fato de ser legitimamente branca, confere a ela grande respaldo para abordar a temática, pois será devidamente ouvida, apoiada nos próprios benefícios que a branquitude lhe permite.

Dentre tantos brancos e brancas, há quem tenha verdadeira dificuldade em declarar-se branco/a de fato, de reconhecer os próprios privilégios e as opressões geradas por sua categoria de raça. Existir como pessoa branca evidencia uma atribuição social de raça, um lugar que deriva do olhar do outro e assegura vantagens ou prejuízos bastante específicos, no que tangem as relações sociais. Mesmo dentro da realidade de ativismo e movimentos sociais como, por exemplo,

\footnotetext{
26 MUNANGA, Kabengele; Gomes, Nilma L. O negro no Brasil de hoje. São Paulo: Global, 2006

27 SOVIK, Liv Rebecca. Aqui ninguém é branco: hegemonia branca e média no Brasil. Rio de Janeiro: Aeroplano, 2009.
} 
o movimento feminista, as noções de pertencimento racial são colocadas em um emaranhado de opressões, onde acabam por não tratar adequadamente as problemáticas raciais 28 .

Essa percepção pode ser complementada com o que, mais tarde, traz Cardoso29, quando versa que pessoas brancas podem ter diferentes consciências de si mesmas. Parte delas, com suficientes recursos subjetivos para se perceberem criticamente e atentarem aos privilégios da sua condição racial. Todavia, outra branquitude, a acrítica, nega as postas discrepâncias raciais. O autor infere que apenas a criticidade dará oportunidade a alianças no combate ao racismo, considerando, obviamente, todas as dimensões do que significa ser branco através dos tempos.

Por essa razão, é importante retomar a atenção para os ecos que as ações da branquitude ocasionam intergeracionalmente. Serra e Schucman 30 concluem que políticas raciais implantadas podem repercutir até nas concepções de humanidade, representações de progresso e desenvolvimento decorridas muitas décadas. Uma profunda pesquisa destas autoras no acervo sobre a Liga Paulista de Higiene Mental, datado do início do século XX, deduz sobre as ainda atuais convicções de superioridade e uniformidade racial brancas.

A branquitude contou sua história dos mais diversos modos, até pela perspectiva do outro. Gomes ${ }^{31}$ revisou na sua tese de doutoramento muito do que se disse das relações raciais de maneira historicizada, na primeira metade do século XX. O documento tratava do percurso da intelectual negra Virgínia Leone Bicudo sob a perspectiva da negritude. Entretanto, há como detectar os traços de branquitude presentes em todo o texto, principalmente quando do registro de aspectos velados da falsa democracia racial no Brasil. Desse modo, a autora entendeu se tratar de uma branquitude cruel, causadora de sofrimentos à

\footnotetext{
28 HUIJG, Dieuwertje D. "Eu não preciso falar que eu sou branca, cara, eu sou Latina!" Ou a complexidade da identificação racial na ideologia de ativistas jovens (não)brancas. Cadernos Pagu, junho de 2011, N. 36, p. 77-116. Doi: https://dx.doi.org/10.1590/S0104-83332011000100005

29 CARDOSO, Lourenço C. Branquitude acrítica e crítica: A supremacia racial e o branco antiracista. Revista Latinoamericana de Ciencias Sociales, Niñez y Juventud, vol 8, N. 1, Janeiro de 2010, p. 607-630

30 SERRA, Lia N., \& SCHUCMAN, Lia V. Branquitude e progresso: a Liga Paulista de Higiene Mental e os discursos paulistanos na contemporaneidade. Estudos e Pesquisas EM PSICOLOGIA, RIO DE JANEIRO, janeiro a abril de 2012, volume 12, N. 1, p. 288-311.

31 GOMES, Janaína D. Os segredos de Virgínia: estudo de atitudes raciais em São Paulo (1945-1955). Tese de Doutorado da Faculdade de Filosofia, Letras e Ciências Humanas, Universidade de São Paulo, São Paulo, 2013. Recuperado de: https://teses.usp.br/teses/disponiveis/8/8134/tde-14032014103244/publico/2013_JanainaDamacenoGomes.pdf
} 
população negra.

Não apenas pessoas negras ou não brancas, mas toda a sociedade é afetada pela performance colonial da branquitude. Nesse sentido, Nogueira ${ }^{32}$ argumenta pela efetiva implementação das ações afirmativas como ferramentas indispensáveis à decolonização. A autora entende que esse processo se daria pela ampliação do acesso das populações negra e indígena aos diferentes níveis de educação, assim como efetivação da Lei 10.639/200333, relativa ao ensino de história e cultura afro-brasileira nas unidades de ensino fundamental e médio.

Das providências a serem adotadas no combate às desigualdades, Schucman ${ }^{34}$ compreende que as mudanças sociais somente serão possíveis mediante a racialização da branquitude. Ela deve ser entendida como categoria racial, qual a negritude e outras demarcações raciais. No entanto, nesse processo de categorização racial emergem outras sub-raças dentro de uma própria raça, de modo que, quanto mais branca a pessoa for fenotipicamente, mais vantagens raciais estão asseguradas a ela. Dessa forma cria-se um padrão hierárquico entre pessoas brancas, que acabam por oprimir umas às outras 35 .

Davis36, quando menciona a percepção da branquitude sobre si mesma, revela os argumentos utilizados para justificar as atrocidades da colonização. A autora declara estarem as pessoas brancas em um lugar de suposto saber, que seria único e verdadeiro. Segundo ela, para os próprios brancos, a colonização foi o necessário remédio à África e seus africanos incivilizados. Não houve, nessa compreensão, violência, mas a indispensável oportunidade de desenvolvimento de povos em atraso.

A perspectiva de progresso e de universalidade não está restrita à realidade

\footnotetext{
32 NOGUEIRA, Simone G. (2013). Ideology of white racial supremacy: colonization and decolonization processes. Psicologia \& Sociedade, volume 25, N. spe, p. 23-32. Doi: https://dx.doi.org/10.1590/S0102-71822013000500004

33 BRASIL. Lei no 10.639, de 9 de janeiro de 2003. Estabelece as diretrizes e bases da educação nacional, para incluir no currículo oficial da Rede de Ensino a obrigatoriedade da temática "História e Cultura Afro-Brasileira", e dá outras providências. Recuperado de: http://www.planalto.gov.br/ccivil_03/leis/2003/l10.639.htm

34 SCHUCMAN, Lia V. Entre o "encardido", o "branco" e o "branquíssimo": raça, hierarquia e poder na construção da branquitude paulistana, Tese de Doutorado do Instituto de Psicologia, Universidade de São Paulo, São Paulo, 2014. Recuperado de: https://www.teses.usp.br/teses/disponiveis/47/47134/tde-21052012-

154521 /publico/schucman_corrigida.pdf

35 SCHUCMAN, Lia V. Sim, nós somos racistas: estudo psicossocial da branquitude paulistana. Psicologia \& Sociedade, abril de 2014, volume 26, N. 1, p. 83-94. Doi: https://dx.doi.org/10.1590/S0102-71822014000100010.

36 DAVIS, Angela Y. Mulheres, Raça e Classe. São Paulo: Boitempo, 2016
} 
estadunidense, mas ao perceber uma realidade geograficamente mais próxima ao Brasil, como a da Argentina, encontra-se um panorama de hegemonia branca, sem espaço para as pessoas que não ascendem diretamente de europeus. É como se estivessem perdidas, nas narrativas da história local, as participações de negros e indígenas na formação do seu povo. As mestiçagens são desconsideradas como se não existissem ${ }^{37}$.

Desse lugar branco de poder, nunca antes questionado, de sabedoria, prazer e conforto que DiAngelo38 intitulou a fragilidade branca. Traz à tona os desconfortos decorrentes das tensões raciais existentes, aos quais a população branca não está habituada. Dá conta dos prejuízos causados pelos privilégios atribuídos às pessoas brancas, em especial, à incapacidade delas de lidar com conflitos raciais, expressa em raiva, culpa, dissonância cognitiva, isolamento e incapacidade emocional. Reafirma a autora, em seus estudos da realidade branca estadunidense, que o fato de a branquitude ter sido "superprotegida", desse tipo de debate e reflexão, desde sempre, a torna mais vulnerável às tensões raciais postas pelo desequilíbrio entre opressores e oprimidos.

Desse modo, se observa que as dimensões territoriais da branquitude não se restringem ao Brasil, além do que ela pode ser percebida nas diferentes fases do desenvolvimento humano, isso inclui a primeira infância. Nesse período, é verificada a introdução da estética e dos parâmetros norteadores brancos na educação de crianças bem pequenas. Desde ali já são dadas as primeiras lições sobre qual o modelo a ser seguido, padrões de identidade específicos 39 .

Apesar das desproporções percebidas, alguns teóricos brancos se dispõem a pensar estratégias para contribuir com a formação de profissionais da psicologia atuantes e sensíveis às questões étnico-raciais, além de encorajar o desenvolvimento de uma branquitude crítica, em resposta aos cursos de psicologia, muitos colaboradores para a manutenção dos contrastes ${ }^{40}$. De outro

\footnotetext{
37 GELER, Lea. (2016). Categorías raciales en Buenos Aires: Negritud, blanquitud, afrodescendencia y mestizaje en la blanca ciudad capital. Runa, volume 37, N.1, p. 71-87.

38 DiANGELO, Robin. Fragilidade branca. Revista ECO-Pós, dezembro de 2018, volume 21, N. 3, p. 3557. https://doi.org/10.29146/eco-pos.v21i3.22528

39 SANTIAGO, Flávio. Branquitude e creche: inquietações de um pesquisador branco. Educar em Revista, agosto de 2019, volume 35, N. 76, p. 305-330. Doi: https://doi.org/10.1590/0104-4060.66099
}

40 MEIRELES, Jacqueline et al . Psicólogas brancas e relações étnico-raciais: em busca de formação crítica sobre a branquitude. Pesqui. prát. psicossociais, São João del-Rei, setembro de 2019, volume 14, N. 3, p. 1-15. 
lado, Cardoso 41 aponta a necessária criticidade para que não continuem se repetindo os padrões dos pesquisadores brancos, que apenas tomam a população negra como objeto de pesquisa, sem perceberem incluídos nas interações raciais existentes.

Butler et.al42. teoriza sobre os desalinhos, construções sociais e distorções cognitivas, responsáveis por fazer a população branca criar arranjos para subjetividades hostis com relação a pessoas negras. Os corpos negros são encarados como uma ameaça constante, como posse do julgamento do opressor. Esse processo é permeado por inferências, no mínimo, incoerentes, potencializando a violência do Estado contra a população negra sob justificativas questionáveis e intenções implícitas, defendem os autores.

Para isso, é necessário situar o sujeito branco como sujeito e corpo racializado, ainda desacostumado a se ver como raça, ao contrário das populações não brancas, desde sempre inseridas em definições raciais pela política, pelas instituições ou para atender à necessidade de autoafirmação43. O olhar crítico sobre si mesmas pode contribuir para que as pessoas brancas incidam com menor com violência sobre as populações oprimidas. Sua condição de vantagem, atribui também poder de letalidade, de tomar decisão sobre a vida e morte de outras pessoas, aspecto ainda mais significativo em tempos de uma pandemia mundial ${ }^{44}$.

Diante dos argumentos apresentados é possível vislumbrar novos caminhos possíveis nos estudos de raça, verificar contribuições teóricas a partir de outras perspectivas que não desconsiderem a branquitude, mas a ponham em foco. Sabendo que a branquitude, em função do pacto narcísico, costuma se invisibilizar e isentar nas discussões raciais, como grupo identitário racial, "só para não passar em branco", este artigo buscou visibilizar e discutir as teorizações que apresentam as diversas performances e classificações atribuídas à raça branca. Apesar disso, mais fontes ainda poderiam ter sido utilizadas, em outros idiomas, regiões

\footnotetext{
${ }^{41}$ CARDOSO, Lourenço C. O branco ante a rebeldia do desejo. Curitiba: Appris, 2020

42 BUTLER, Judith et. al. Em perigo/perigoso: racismo esquemático e paranoia branca. Educação e Pesquisa, 2020, 46, e460100302. Doi: https://doi.org/10.1590/s1517-97022020460100302.

43 ORTIZ-PIEDRAHÍTA, Vanessa. (2020). Subjetivación de la blanquitud por jóvenes universitarios: un estudio comparativo. Revista Latinoamericana de Ciencias Sociales, Niñez y Juventud, abrilde 2020, volume 18, N. 1, p. 183-206. Doi: https://doi.org/10.11600/1692715x.18109

44 Eurico, Márcia et. al. Racismo e novo pacto da branquitude em tempos de pandemia: desafios para o Serviço Social. Serviço Social \& Sociedade, abril de 2021, N. 140, p. 84-100. Doi: https://dx.doi.org/10.1590/0101-6628.239
} 
geográficas, contextos sociais e abarcar novas definições que possam ter sido deixadas de lado. Em vez de conferir respostas, esse estudo propõe reflexões apoiadas no pensamento dos autores e autoras que antecederam esse trabalho, ao mesmo tempo, contribuindo para que essas ideias sejam validadas, refutadas, ou contadas de maneira diferente, no curso temporal analisado e além dele.

\section{Considerações Finais}

A análise criteriosa dos textos teóricos aponta que a branquitude, em suas diversas representações, configura-se um agente central mantenedor do racismo, assim como as opressões de classe e gênero. Nas diferentes conceituações trazidas, a figura do indivíduo branco está, invariavelmente, em posição de poder e de subjugação do que é diferente de si. Foram identificados os problemas da não racialização e os prejuízos centenários dessa relação de poder. É um panorama diverso e complexo, que compreende pessoas com ou sem consciência de sua branquitude, com variados níveis de privilégios, expressos em diferentes países de maneira diferente.

Falar sobre branquitude é, em si, algum avanço nas produções científicas sobre os estudos de raça, em resposta ao longo período em que apenas se falou sobre negritude e grupos raciais minorizados. Porém, não se pode desprezar a capacidade da branquitude de se transmutar com o passar do tempo, de criar refinadas e versáteis tecnologias de opressão para seguir assumindo à força as rédeas das relações humanas. Para tanto, será importante acumular ainda mais estudos sobre esse assunto intricado, que indica, pela maneira como a branquitude performa, dificuldades no entendimento dessas relações raciais. A branquitude não deseja ser encontrada, mapeada, analisada ou questionada.

Outro ponto que não deve ser desprezado é que o entendimento da branquitude e do seu funcionamento denunciará os arranjos sociais em suas desigualdades e os privilégios da população branca. É preciso contar com a tendência a não dispensar o conforto dos privilégios e as possíveis resistências inscritas nesse processo de desconstrução. A branquitude criou o conceito de negritude e os abismos sociais decorrentes da própria opressão. Ela também possui responsabilidade de criar uma convivência mais harmoniosa entre as diferentes identidades racializadas. Portanto, este artigo intenta colaborar para estudos atuais e futuros no recorte de raça, em especial com a literatura sobre branquitude. 


\section{Referências}

ALMEIDA, Silvio L. Racismo estrutural. São Paulo: Pólen, 2019.

BACELAR, Jeferson. A hierarquia das raças: Negros e Brancos em Salvador. Rio de Janeiro: Pallas, 2008.

BUTLER, Judith et. al. Em perigo/perigoso: racismo esquemático e paranoia branca. Educação e Pesquisa, 2020, 46, e460100302. https://doi.org/10.1590/s151797022020460100302

BRASIL. Lei $n^{\circ}$ 10.639, de 9 de janeiro de 2003. Estabelece as diretrizes e bases da educação nacional, para incluir no currículo oficial da Rede de Ensino a obrigatoriedade da temática "História e Cultura Afro-Brasileira", e dá outras providências. Recuperado de: http://www.planalto.gov.br/ccivil_03/leis/2003/110.639.htm

CARDOSO, Lourenço C. Branquitude acrítica e crítica: A supremacia racial e o branco anti-racista. Revista Latinoamericana de Ciencias Sociales, Niñez y Juventud, vol. 8, N. 1, Janeiro de 2010, p. 607-630.

CARDOSO, Lourenço C. O branco ante a rebeldia do desejo. Curitiba: Appris, 2020.

CARONE, Iray; Bento, Maria Aparecida S. Psicologia social do racismo: estudos sobre branquitude e branqueamento no Brasil. Petrópolis: Vozes, 2003.

CONSELHO FEDERAL DE PSICOLOGIA. Resolução CFP n. ${ }^{\circ}$ 010: Código de Ética do Profissional Psicólogo. Brasília: CFP, 2005.

CONSELHO FEDERAL DE PSICOLOGIA. Relações Raciais: Referências técnicas para a atuação de psicólogas(os). Brasília: CFP, 2017.

COROSSACZ, Valéria R. Relatos de branquitude entre um grupo de homens brancos do Rio de Janeiro. Revista Crítica de Ciências Sociais, dezembro de 2014, N. 105, p. 43-64. https://dx.doi.org/10.4000/rccs.5790

DAVIS, Angela Y. Mulheres, Raça e Classe. São Paulo: Boitempo, 2016

DiANGELO, Robin. Fragilidade branca. Revista ECO-Pós, dezembro de 2018, volume 21, N. 3, p. 35-57. https://doi.org/10.29146/eco-pos.v21i3.22528

Eurico, Márcia et. al. Racismo e novo pacto da branquitude em tempos de pandemia: desafios para o Serviço Social. Serviço Social \& Sociedade, abril de 2021, N. 140, p. 84-100. https://dx.doi.org/10.1590/0101-6628.239

FANON, Frantz. Pele negra, máscaras brancas. Salvador: EDUFBA, 2008.

GELER, Lea. (2016). Categorías raciales en Buenos Aires: Negritud, blanquitud, afrodescendencia y mestizaje en la blanca ciudad capital. Runa, volume 37, N.1, p. 71-87.

GOMES, Janaína D. Os segredos de Virgínia: estudo de atitudes raciais em São Paulo (1945-1955). Tese de Doutorado da Faculdade de Filosofia, Letras e Ciências Humanas, Universidade de São Paulo, São Paulo, 2013. Recuperado de: https://teses.usp.br/teses/disponiveis/8/8134/tde-14032014-

103244/publico/2013_JanainaDamacenoGomes.pdf.

HOHENDORFF, Jean V. Como escrever um artigo de revisão de literatura. In S. H. Koller, M. 
C. P. P. Couto, \& J. V. Hohendorff (Orgs). Manual de produção científica (p. 39-54). São Paulo: Penso, 2014.

HUIJG, Dieuwertje D. "Eu não preciso falar que eu sou branca, cara, eu sou Latina!" Ou a complexidade da identificação racial na ideologia de ativistas jovens (não)brancas. Cadernos Pagu, junho de 2011, N. 36, p. 77-116. https://dx.doi.org/10.1590/S0104-83332011000100005

MEIRELES, Jacqueline et al. Psicólogas brancas e relações étnico-raciais: em busca de formação crítica sobre a branquitude. Pesqui. prát. psicossociais, São João delRei, setembro de 2019, volume 14, N. 3, p. 1-15.

MUNANGA, Kabengele; Gomes, Nilma L. O negro no Brasil de hoje. São Paulo: Global, 2006.

NOGUEIRA, Simone G. (2013). Ideology of white racial supremacy: colonization and de-colonization processes. Psicologia \& Sociedade, volume 25, N. spe, p. 23-32. https://dx.doi.org/10.1590/S0102-71822013000500004

OLIVEIRA, Daniele de; Resende, Viviane de Melo. Branquitude, discurso e representação de mulheres negras no ambiente acadêmico da UFBA. Bakhtiniana: Revista de Estudos do Discurso, dezembro de 2020, volume 15, N. 4, p. 149-171. https://dx.doi.org/10.1590/2176-457347682

ORTIZ-PIEDRAHÍTA, Vanessa. (2020). Subjetivación de la blanquitud por jóvenes universitarios: un estudio comparativo. Revista Latinoamericana de Ciencias Sociales, Niñez y Juventud, abrilde 2020, volume 18, N. 1, p. 183206. https://doi.org/10.11600/1692715x.18109

RAMOS, Alberto G. Introdução crítica à sociologia brasileira. Rio de Janeiro: Editora da UFRJ, 1995.

SANTIAGO, Flávio. Branquitude e creche: inquietações de um pesquisador branco. Educar em Revista, agosto de 2019, volume 35, N. 76, p. 305-330. https://doi.org/10.1590/0104-4060.66099

SERRA, Lia N., \& SCHUCMAN, Lia V. Branquitude e progresso: a Liga Paulista de Higiene Mental e os discursos paulistanos na contemporaneidade. Estudos e Pesquisas EM PSICOLOGIA, RIO DE JANEIRO, janeiro a abril de 2012, volume 12, N. 1 , p. 288-311.

SCHUCMAN, Lia V. Entre o "encardido", o "branco" e o "branquíssimo": raça, hierarquia e poder na construção da branquitude paulistana, Tese de Doutorado do Instituto de Psicologia, Universidade de São Paulo, São Paulo, 2014. Recuperado de: $\quad$ https://www.teses.usp.br/teses/disponiveis/47/47134/tde-21052012154521/publico/schucman_corrigida.pdf

SCHUCMAN, Lia V. Sim, nós somos racistas: estudo psicossocial da branquitude paulistana. Psicologia \& Sociedade, abril de 2014, volume 26, N. 1, p. 83-94. Doi: https://dx.doi.org/10.1590/s0102-71822014000100010.

SOUZA, Neusa S. Tornar-se Negro. Rio de Janeiro: Edições Graal, 1983.

SOVIK, Liv Rebecca. Aqui ninguém é branco: hegemonia branca e média no Brasil. Rio de Janeiro: Aeroplano, 2009. 